\title{
Nurses' Knowledge, Practice, and Attitude Regarding Burn Injury Management
}

\author{
Rasha Kamel Mohammed (1), Manal Salah Hassan (2), Inshrih Roshdy Mohammed (3)
}

1. Clinical instructor- Technical Institute of Nursing - Beni-Suief University

2. Professor of Medical Surgical Nursing Faculty of Nursing Department - Ain Shams University

3. Assistant Professor of Medical Surgical Nursing Department Faculty of Nursing - Minia University

\begin{abstract}
Background: Burn is bodily injury resulting from exposure to heat, electricity, or some radiations, marked by varying degrees of skin destruction and hyper anemia often with the formation of watery blisters Aim of study: to assess Nurses' Knowledge, Practice and, Attitude, Regarding Burn Injury Management. Subjects and methods: Descriptive study. The study was conducted at three hospitals (Beni-Suef general hospital, Minia general hospital and, Minia university hospital)first and second hospital affiliated to ministry of health, the third one affiliated to ministry of higher education. Forty nurses where included in the current study sample. Three tools of data collection were used to carry out this study namely, tool 1): Structured Self-Administered Questionnaire that include two parts; part 1): demographic characteristics, and part 2): nurse's knowledge, Tool П-: Nurses' observational checklists procedure, and Tool ІП: Structured nurse's attitude scales. Results: majority of the studied nurses (82.5\%) had unsatisfactory knowledge, and, (100\%) had unsatisfactory practices and negative attitude regarding burn injury management. Conclusion and recommendations: Most of nurses had shortage knowledge level, poor practice and, negative attitude due to lack of educational program, lack of training and, no update to nurse's performances so, the current study recommended that importance of Provide continuous education and update for nurses regarding evidence based nursing practices about burn patients and, provide sufficient supplies and equipment from hospital administration for nurses to perform their practice in a high quality, safe and in efficient way

Keywords: Nurses' attitude, knowledge and, practice, and burn injury
\end{abstract}

\section{Introduction}

Skin is the largest and primary protective organ in the body, covering the body's entire external surface and serving as a first-order physical barrier against the environment. Skin is the largest organ of the body, the skin spans 3000 square inches (approximately 2 square meters) and comprises $15 \%$ of the entire human body's weight. It is a dynamic organ that grows, differentiates, and routinely renews itself every 26-42 days (Wysocki, 2019).

Burn injuries are among the most devastating of all injuries and a major global public health crisis. Burns are the fourth most common type of trauma worldwide, following traffic accidents, falls, and interpersonal violence. Approximately 90 percent of burns occur in low- to middleincome countries, regions that generally lack the necessary infrastructure to reduce the incidence and severity of burns (Murray,2020).

Burns are a global public health problem, accounting for an estimated 180000 deaths annually, and here in the United States, at least 40,000 people may require hospitalization for burn injuries, and the rate of deaths from burns is currently over 7 times higher in low- and middleincome countries than in high-income countries. Burns are among the leading causes of disability in adjusted life-years (DALYs) lost in low- and middle-income countries, burn accidents happen every 15 seconds (Murray,2020).

Burn takes place when the skin comes into contact with a heat source, there are many causes of burns, dry heat such as fire or a hot object, wet heat such as boiling water, steam, or hot liquids, radiation such as from the sun or nuclear radiation, friction such as rubbing forces with an object electricity, and certain chemicals can all cause burns. Minor burns can cause reddened skin, pain, and swelling. The skin may blister and peel. Severe burns can cause white or blackened and charred skin (Ronald,2016).

More severe burns need medical management, may leave scars, and carry a higher risk of complications, such as: Infection, burns cause open wounds where bacteria and other germs can enter the body, the resulting infections can be minor and easily treatable or can develop into more severe infections, such as sepsis, sepsis occurs when the infection enters a person's bloodstream and can be life-threatening (Mehta,2019).

Dehydration, burns cause the body to lose fluid, losing excessive amounts of fluid can cause dehydration, which can affect the volume of blood flowing through the body. Low body temperature, a person's skin helps to regulate their body temperature, when a burn damages the skin extensively, the resulting heat loss can result in hypothermia, when a person's body temperature suddenly drops to dangerously low levels (Debra, 2018).

Burns are characterized by the degree to which they affect the skin, First-degree burns, affects only the outer layer of skin, known as the epidermis. Skin that has suffered a firstdegree burn is typically red and dry, but lacks blister formation. Second-degree burns, it can be superficial, partial or, deep partial thickness and will include the epidermis and part of the dermis, the layer of skin below the surface. In a partial-thickness second-degree burn, some of the upper dermis is affected, while a deep partial-thickness seconddegree burn will destroy all of the lower dermis. (Joye, 2020).

Third-degree burns full-thickness burns, not only are the epidermis and dermis destroyed, but the underlying muscles, tendons and bones may also be damaged, skin appear White or black/brown, non-blanching. A thirddegree burn causes severe damage to nerve endings and 
permanent tissue damage and scarring. It heal by contracture in more than 8 weeks. Skin grafting will likely be necessary, as will functional and/or cosmetic surgery ( Evers, 2018).

Fourth-degree burns, These burns are the most severe out of all the classifications, they affect all layers of skin, and reach down to the fat, bone, tissues, and muscles, the appearance of the burn may be black or charred, and nerve damage may cause the victim to feel no pain. Because they reach so deep into the victim's body, they can cause permanent damage or even death if not immediately treated by a medical professional (Carol, 2019).

A nurse who cares for a patient with burn injury should be knowledgeable about changes that occur after a burn, as well as astute assessment skills to detect subtle changes in the patient's condition and know how to deal with patients. Providing care to the burn-injured patient is a very challenging and, ultimately, rewarding profession for a nurse. Skills needed is varied and includes comprehensive clinical assessment and monitoring, pain management, wound care and psychosocial support (El-Sayed, et al., 2019).

Meanwhile, the nurses play an important role in this regard. The nurses who provide care services for the burn patients should obtain adequate knowledge on the physiologic effects after caused burning and possess the rapid analysis and decision-making on trivial changes occurred in the patient status. The beginning of the rehabilitation could establish compassionate and sympathetic relationship with the patients and their families. The audit cycle is a quality improvement intervention used to decrease evidence-practice gaps (Ghezeljeh, et al., 2019).

Burn care nurses help treat burn victims from the initial trauma treatment to recovery and post-trauma therapy. Burn unit nurses can get a position with only an associate's degree, but certification and higher education can provide an edge over other candidates (Ali, et al., 2018). From my observation the new employment nurses at burn units in previous places developed a lot of knowledge and practices regarding burn care and are qualified nurses able to managing burn patient.

A burn care nurse specializes in the care of patients who suffer from burn injuries, and in many cases, have also experienced other kinds of trauma. The burn care nurse treats and monitors burn wounds, and plays a critical role in the assessment of emotional and psychological trauma that so often accompanies a burn injury. Optimal care of the burn patient requires a distinctive multidisciplinary approach. Positive patient outcomes are dependent on the composition of the burn care team and close collaboration among its members; at the center of this team is the burn nurse, the coordinator of all patient care activities (Tirgari, et al., 2018).

\section{Significance of the study:}

Great advances have been made in the care of patients with burn injury. In the mid-twentieth century, burn shock claimed many patients' lives. If shock did not cause death, infection or respiratory insufficiency did. With improvements in fluid resuscitation, better critical care management, and the trend toward early excision and grafting, mortality rates have decreased. To provide comprehensive, holistic care to patients with burn injury, close collaboration is required among members of the multi- disciplinary team. The patient's response to a major burn injury is dramatic and involves multisystem alterations. Knowledge of local and systemic changes associated with patient needs is essential in providing care, which places extraordinary demands on the nurse in a burn practice who must be both a specialist and a broad-based generalist (Kenetra, et al., 2013). So

\section{Aim of the study}

This study aimed to assess Nurses' Knowledge, practice and, Attitude Regarding Burn Injury management. Research question:

1- What are levels of knowledge?

2- Are there a correlation between nurses' total knowledge, practice and attitude?

\section{Subjects and Methods \\ Research design:}

Descriptive research design was used in carrying out the current study.

\section{Setting:}

The current study was conducted at three hospitals first hospital (Beni-Suef general hospital) (burn and emergency unit). Beni-Suef general hospital affiliated to the ministry of health, Beni-Suef government, Egypt. The study was at emergency department is located at first floor it consist of 7 rooms according to each specialty surgery emergency room contain 3 beds, burn unit is located at third floor it consist of 7 rooms each one contains 5 beds.

Second and third hospital (Minia university hospital and Minia general hospital), Minia university hospital at (burn unit). Which affiliated to the ministry of higher education Minia government, Egypt , the burn unit is located at fourth floor it consist of 5 rooms each one contains 6 beds. Minia general hospital (burn unit). Which affiliated to the ministry of health Minia government, the burn unit is located at second floor it consist of 4 rooms each one contains 8 beds. In all hospitals found assess service such as X-ray department (CT, MMR, chest X-ray), lab department and pharmacy for inpatient \& out patient

\section{Subjects:}

Studied sample include all staff nurses who were on duty in previous three hospitals mentioned in study setting, their total number were (40) subject

\section{Data collection tools:}

Three tools were used in the current study developed by researcher after reviewed extensive relevant literature and constructed in Arabic form:

Tool I: Structured Self-Administered Questionnaire : it included two parts-:

Part I; its purpose to assess personal characteristics of nurses such as (age, sex, and level of education, year of graduation and, years of experience)

\section{Part II; Nurses Knowledge:}

To evaluate nurses' knowledge regarding burn injury care, it include eighty(80) multiple choice questions regarding burn injury regard pre/post studied program such as: Anatomy and physiology of the skin, pathophysiology of burn, causes of burn, degrees of burn and, clinical manifestation and management of burn in each burn stage.

Scoring system: items total global score of 80 for 80 items, was rated on (correct choice or in correct choice) with scoring 
( correct choice $=1$, incorrect choice $=\mathbf{0}$ ). The total score of this scale classified into two results based on the following:

Satisfactory $*$ Equal or $>60 \%$ this mean $(48 / 80$ scores $)$

Un satisfactory $*<60 \%$ this mean $(48 / 80$ scores $)$

\section{Tool П-: Nurses' observational checklists:}

It was ben used to evaluate nurses' practice regarding care of patients with burn injury, it consists of three parts:

1-Burn wound dressing procedure: it was included 41 steps, as (e.g. preparation of patient and, preparation of environment and equipment, assessment, pre dressing medication/ pain relief, and, burns dressing steps)

2-Scar management procedure: it was included 17 steps, as (e.g. Massage, Pressure garments, Splints and, Stretching).

3-Rehabilitations exercises according to their burn site : : it was included 42 steps, as (e.g. stretching exercises, aerobic walk exercises, muscles strengthening exercises and, , Stretching exercises to help with tightness).

Scoring system: all nursing practice checklist procedure was rated on (done or not done) with scoring (done $=1$, not done $=\mathbf{0}$ ), total global score of steps 100 for 100steps, total score classified into two results based on the following:

Satisfactory * Equal or $>70 \%$ this mean $(70 / 100$ scores)

Un satisfactory $*<70 \%$ this mean $(70 / 100$ scores $)$

\section{Tool III: Structured nurse's attitude scale:}

It was been used to assess nurses' attitude during providing the care to the patients with burn injury pre / post the current study program.

Scoring system: items total global score of 60 for 20 items, was rated on three rank as (always $=3$, sometimes $=2$, never $=1$ ). The total score of this scale classified into two results based on the following:

Positive $\quad *$ Equal or $<60 \%$ this mean (36/60 scores)

Negative $*>60 \%$ this mean $(36 / 60$ scores $)$

\section{Validity}

The current study tools were examined by a panel of five academic experts opinion in the field of medical surgical nursing departments ( assistant prof of medical surgical) \{Helwan university and, Banha university $\}$ All jury members $(100 \%)$ were agreed that current study tools and its validity relevant with the aim of the study.
Reliability:-

Cronbach's alpha test ideal average to insure reliability of study, testing internal consistency was performed for evaluating structured self-administered questionnaire, nurses' observational checklist and, Structured nurse's attitude scale it was $(0.96,0.71$ and 0.86$)$ respectively.

Fieldwork:

The current study was conducted by preparing of different data collection tools, in addition to, obtaining formal paper agreement which was taken in duration one week before conducting the current study. The researcher acted collection of the current study data from its setting on daily basis during morning or afternoon shifts.

The researcher started data collection structured selfadministered questionnaire (Tool I: Part I : nurses personal characteristics data and, Tool I:part II: nurses knowledge) filled by nurse within 20-30 minute. While (Tool II: Nurses' observational checklist procedure) and (Tool III: Structured nurse's attitude scale) are filled by the researcher within 20-30 minutes for every procedure ..

Ethical Considerations:

An official permission to conduct the study was obtained from the Ethical committee in the Faculty of Nursing, Dean of Nursing Faculty and the Manager of Minia University Hospital, Minia General Hospital and Beni-Suef General Hospital, the Head of the Burn Departments in all hospitals and agreement from Egypt Academic for Research Center and Technology to carry out this study. To carry out this study. Subject's participation in this study was voluntary and each involved subject was informed about the purpose, procedure, benefits, and nature of the study, and that he/she had the right to withdraw from the study at any time without any rationale, then oral consents were obtained. Confidentiality and anonymity of each subject were ensured through coding of all data and protecting the obtained data. Subjects were informed that obtained data will not be included at any further researches without a second oral consent.

\section{Statistical analysis:}

Data entry and statistical analysis were done using (SPSS) statistical software package. Quality control was at the stage of coding and data entry. Data were presented using descriptive statistics in the form of frequencies and percentage for qualitative variables; mean and standard deviation for quantitative variable. Qualitative categorical variables were compared Chi-square (X2) test. Statistical significance was considered at $(\mathrm{P}$-value $<0.05)$.

\section{Results:}

Table (1): Personal characteristics of the studied nurses $(n=40)$.

\begin{tabular}{|c|c|c|}
\hline Demographic characteristics & No. & $\%$ \\
\hline \multicolumn{3}{|l|}{ Age } \\
\hline$-\quad<20$ & $\varepsilon$ & 10 \\
\hline - $\quad 20:<40$ years & 20 & 50 \\
\hline$-\quad \geq 40$ years & 16 & 40 \\
\hline Mean \pm SD & \multicolumn{2}{|c|}{$33.5 \pm 9,91$} \\
\hline \multicolumn{3}{|l|}{ Gender } \\
\hline - Male & 6 & 15 \\
\hline$-\quad$ Female & 34 & 85 \\
\hline \multicolumn{3}{|l|}{ Qualifications } \\
\hline$-\quad$ Nursing diploma & 8 & 20 \\
\hline - $\quad$ Technical nursing institute & 20 & 50 \\
\hline - $\quad$ Bachelor of nursing & 6 & 15 \\
\hline - $\quad$ Master degree & 4 & 10 \\
\hline$-\quad$ Doctorate degree & 2 & 5 \\
\hline \multicolumn{3}{|l|}{ Experience in burn department } \\
\hline$-\quad<5$ yrs. & 12 & 30 \\
\hline
\end{tabular}


Minia Scientific Nursing Journal (Print - ISSN 2537-012X) (Online - ISSN 2785-9797) Vol. (9) No. (1) June 2021

\begin{tabular}{|c|l|l|}
\hline Demographic characteristics & No. & $\mathbf{\%}$ \\
\hline$-\quad 5-10$ yrs. & 6 & 15 \\
\hline$-\quad>10$ yrs. & 22 & 55 \\
\hline Training on burn care & & \\
\hline$-\quad$ Yes & 24 & 60 \\
\hline- No & 16 & 40 \\
\hline
\end{tabular}

Table (1) shows that half (50\%) of the studied nurses had 20 to $<40$ years old, majority ( $85 \%)$ of them were female. Half of the studied nurses (50\%) were graduated from technical nursing institute and more than half among them (55\% \& $60 \%)$ had more than 10 years of experience, and they were attended training about burn care

Table ( $\left.{ }^{r}\right)$ : Personal distribution of nurses' total knowledge, practice, and attitude regarding burn injury managment $(n=40)$.

\begin{tabular}{|l|l|l|}
\hline Items & No. & $\%$ \\
\hline Nurses total knowledge & & \\
\hline$-\quad$ Satisfactory knowledge & 7 & 17.5 \\
\hline- Unsatisfactory knowledge & 33 & 82.5 \\
\hline Nurses total performance & & \\
\hline- Satisfactory performance & 0 & 0 \\
\hline- Unsatisfactory performance & 40 & 100 \\
\hline Nurses total attitude & & \\
\hline$-\quad$ positive attitude & 0 & 0 \\
\hline$-\quad$ Negative attitude & 40 & 100 \\
\hline
\end{tabular}

Table (2) shows that, majority of the studied nurses (82.5\%) had unsatisfactory knowledge regarding burn injury. All nurses $(100 \%)$ had unsatisfactory performance and had bad attitude regarding burn injury.

Table (3): The relation between nurses' knowledge and their personal characteristics

\begin{tabular}{|c|c|c|c|c|}
\hline \multicolumn{2}{|l|}{ Demographic characteristics } & \multirow{2}{*}{$\begin{array}{l}\text { Knowledge } \\
\text { Mean } \pm \text { SD }\end{array}$} & \multirow{2}{*}{$\begin{array}{l}\text { t/f } \\
\text { test }\end{array}$} & \multirow[t]{2}{*}{$\mathbf{P}$} \\
\hline \multirow{2}{*}{\multicolumn{3}{|c|}{ Age }} & & \\
\hline & & & \multirow[t]{4}{*}{4.96} & \multirow[t]{4}{*}{.084} \\
\hline$-<20$ & $\varepsilon$ & $0.33 \pm 0.57$ & & \\
\hline - 20:<40 years & 20 & $0.15 \pm 0.22$ & & \\
\hline$-\geq 40$ years & 16 & $0.13 \pm 0.35$ & & \\
\hline \multicolumn{3}{|l|}{ Gender } & \multirow[t]{3}{*}{0.222} & \multirow[t]{3}{*}{.399} \\
\hline - Male & 6 & $0.00 \pm 0.00$ & & \\
\hline - Female & 34 & $0.12 \pm 0.34$ & & \\
\hline \multicolumn{3}{|l|}{ Qualifications } & \multirow[t]{6}{*}{2.58} & \multirow[t]{6}{*}{$.042 *$} \\
\hline - Nursing diploma & 8 & $0.25 \pm 0.46$ & & \\
\hline - Technical nursing institute & 20 & $0.11 \pm 0.32$ & & \\
\hline - Bachelor of nursing & 6 & $0.00 \pm 0.00$ & & \\
\hline - Master degree & 4 & $0.00 \pm 0.00$ & & \\
\hline - Doctorate degree & 2 & $0.00 \pm 0.00$ & & \\
\hline \multicolumn{3}{|l|}{ Experience in burn department } & \multirow[t]{4}{*}{9.12} & \multirow[t]{4}{*}{$.003^{*}$} \\
\hline$-<5$ yrs. & 12 & $0.19 \pm 0.32$ & & \\
\hline - 5-10 yrs. & 6 & $0.17 \pm 0.41$ & & \\
\hline$->10$ yrs. & 22 & $0.12 \pm 0.36$ & & \\
\hline \multicolumn{3}{|l|}{ Training on burn care } & \multirow[t]{3}{*}{5.28} & \multirow[t]{3}{*}{$.014 *$} \\
\hline - Yes & 24 & $0.54 \pm 0.21$ & & \\
\hline - No & 16 & $0.23 \pm 0.47$ & & \\
\hline
\end{tabular}

Table (3) shows that there is a statistically significant relation between nurse's knowledge and their qualifications, experiences in burn department, and training on burn care. While, there is no statistically significant relation between nurse's knowledge and their gender and age.

Table (4): The relation between nurses' practice and their personal characteristics

\begin{tabular}{|c|c|c|c|c|}
\hline \multirow[t]{2}{*}{ Demographic characteristics } & & Practice & \multirow{2}{*}{$\begin{array}{l}\mathbf{t} / \mathbf{f} \\
\text { test }\end{array}$} & \multirow[t]{2}{*}{$\mathbf{P}$} \\
\hline & & Mean \pm SD & & \\
\hline \multicolumn{3}{|l|}{ Age } & \multirow[t]{4}{*}{2.41} & \multirow[t]{4}{*}{.254} \\
\hline$-<20$ & $\varepsilon$ & $0.75 \pm 0.51$ & & \\
\hline$-20:<40$ years & 20 & $0.85 \pm 0.34$ & & \\
\hline$-\geq 40$ years & 16 & $0.63 \pm 0.52$ & & \\
\hline \multicolumn{3}{|l|}{ Gender } & \multirow[t]{3}{*}{0.24} & \multirow[t]{3}{*}{.532} \\
\hline - Male & 6 & $0.68 \pm 0.57$ & & \\
\hline - Female & 34 & $0.76 \pm 0.34$ & & \\
\hline \multicolumn{3}{|l|}{ Qualifications } & \multirow[t]{6}{*}{8.16} & \multirow[t]{6}{*}{$0.043^{*}$} \\
\hline - Nursing diploma & 8 & $0.88 \pm 0.53$ & & \\
\hline - Technical nursing institute & 20 & $0.65 \pm 0.49$ & & \\
\hline - Bachelor of nursing & 6 & $0.83 \pm 0.41$ & & \\
\hline - Master degree & 4 & $0.11 \pm 0.00$ & & \\
\hline - Doctorate degree & 2 & $0.21 \pm 0.71$ & & \\
\hline \multicolumn{3}{|l|}{ Experience in burn department } & \multirow[t]{3}{*}{7.42} & \multirow[t]{3}{*}{$0.033^{*}$} \\
\hline$-<5$ yrs. & 12 & $0.83 \pm 0.39$ & & \\
\hline$-5-10 \mathrm{yrs}$ & 6 & $0.67 \pm 0.52$ & & \\
\hline
\end{tabular}


Minia Scientific Nursing Journal (Print - ISSN 2537-012X) (Online - ISSN 2785-9797) Vol. (9) No. (1) June 2021

\begin{tabular}{|l|l|l|l|l|}
\hline$->10$ yrs. & 22 & $0.73 \pm 0.46$ & & \\
\hline Training on burn care & & & 4.35 & $0.002^{*}$ \\
\hline- Yes & 24 & $0.75 \pm 0.44$ & & \\
\hline - No & 16 & $0.67 \pm 0.42$ & & \\
\hline
\end{tabular}

Table (4) shows that there is a statistically significant relation between nurse's practice and their qualifications, experiences in burn department, and training on burn care. While, there is no statistically significant relation between nurse's knowledge and their gender and age.

Table (5): The relation between nurses' total attitude and their personal characteristics

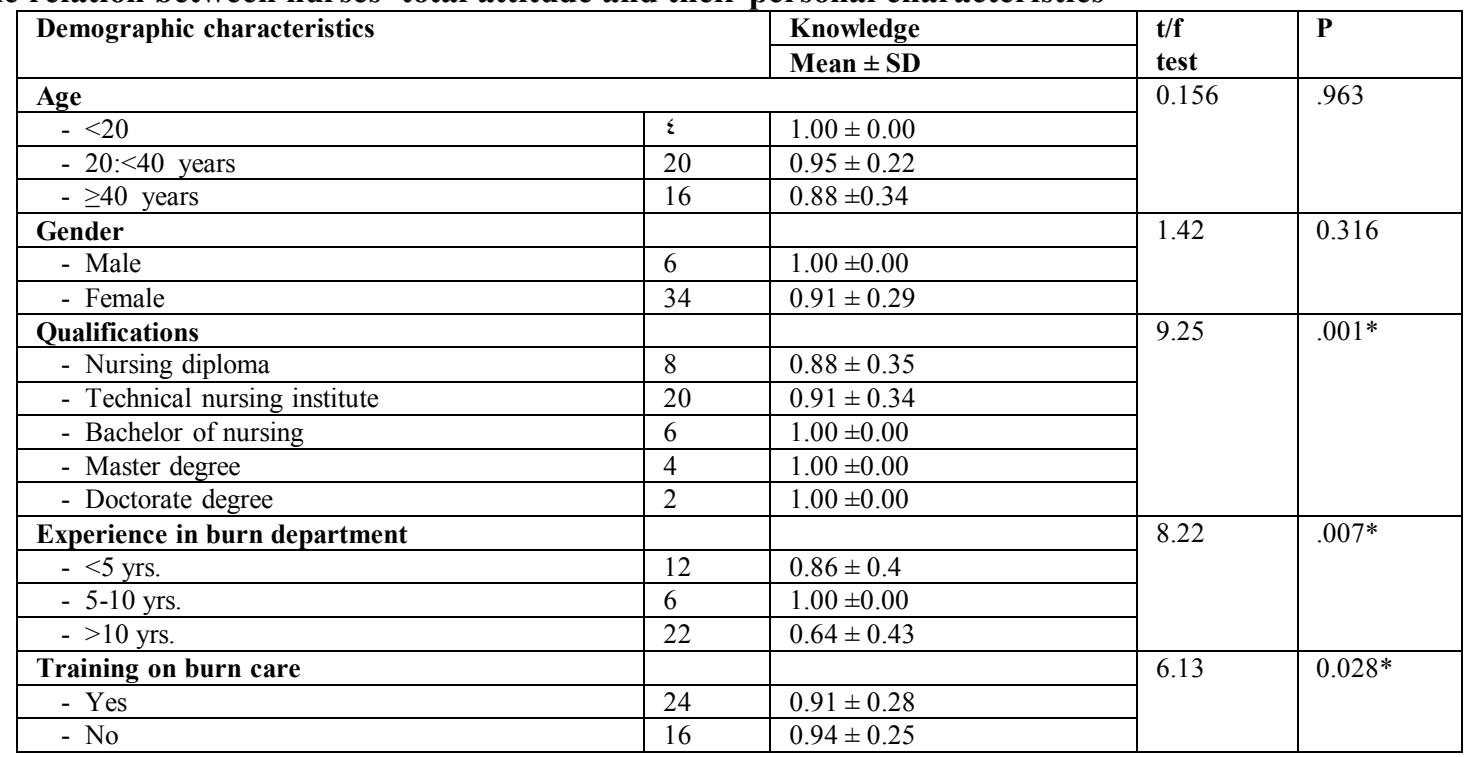

Table (5) shows that there is a statistically significant relation between nurse's attitude and their qualifications, experiences in burn department, and training on burn care. While, there is no statistically significant relation between nurse's knowledge and their gender and age.

Table (6): correlation between nurses' total knowledge, practice and attitude scores

\begin{tabular}{|l|l|l|l|l|}
\hline \multicolumn{2}{|c|}{} & $\begin{array}{l}\text { Total } \\
\text { knowledge } \\
\text { scores }\end{array}$ & $\begin{array}{l}\text { Total practice } \\
\text { scores }\end{array}$ & Total attitude scores \\
\hline \multirow{2}{*}{ Total knowledge scores } & $\mathbf{R}$ & 1 & .824 & .627 \\
\cline { 2 - 5 } & $\mathbf{p}$-value & - & $.000^{* *}$ & $.000^{* *}$ \\
\hline \multirow{2}{*}{ Total practice scores } & $\mathbf{R}$ & .824 & 1 & .620 \\
\cline { 2 - 5 } & $\mathbf{p}$-value & $.000^{* *}$ & - & $.000^{* *}$ \\
\hline \multirow{2}{*}{ Total attitude scores } & $\mathbf{R}$ & .627 & .620 & 1 \\
\cline { 2 - 5 } & $\mathbf{p}$-value & $.000^{* *}$ & $.000^{* *}$ & - \\
\hline
\end{tabular}

(*) statistically significant $\mathrm{p}<0.05$

$(* *)$ high statistically significant $\mathrm{p}<0.01$

Table (6) shows that there is a positive correlation between nurses' total knowledge, practice and attitude scores

\section{Discussion:}

Burn injury is bodily injury resulting from exposure to heat, electricity, or some radiations, marked by varying degrees of skin destruction and hyperaemia often with the formation of watery blisters, most people can recover from burns without serious health consequences, depending on the cause and degree of injury, more serious burns require immediate emergency medical care to prevent complications and death (hunt, 2017). Burns are tissue damage that results from heat, overexposure to the sun or other radiation, or chemical or electrical contact. Burns can be minor medical problems or life-threatening emergencies. The treatment of burns depends on the location and severity of the damage. Sunburns and small scalds can usually be treated at home. Deep or widespread burns need immediate medical attention. Some people need treatment at specialized burn centres and months long follow-up care (Mayo ,2019).
So, the current study aims to evaluate nurses' knowledge, attitude, and performance Regarding Burn Injury through: evaluating nurses' knowledge regarding the burn injury, and evaluating nurses' practices and attitude regarding the care of patient with burn injury

Regarding demographic characteristics, the current study showed that half of the studied nurses had 20 to $<40$ years old, majority of them were female. Half of the studied nurses were graduated from technical nursing institute and more than half among them had more than 10 years of experience, and they were attended training about burn care

This study was agreement with Melo, \& Lima, (2017) who conducted entitled "Cost of nursing most frequent procedures performed on severely burned patients" and found majority of nurses were female, and more than half of them were graduated from technical nursing institute. Conversely, this study was disagreement with Ardebili,et al., (2017) who conducted entitled "Effect of multimedia self-care education 
on quality of life in burn patients" and found that majority of nurses had 30 to $<40$ years old, and more than three quarter had more than 10 years of experience.

Concerning nurses' total knowledge, attitude, and performance regarding burn injury, the current study revealed that, majority of the studied nurses had unsatisfactory knowledge regarding burn injury. All nurses had unsatisfactory performance and had bad attitude regarding burn injury. This due to lack of training of burn nurses and newly employed nurses need a lot of training program.

This study was agreement with Meschial, \& Oliveira, (2017) who conducted entitled "Initial care for burned patients in academic nursing education" and found that majority of nurses had unsatisfactory knowledge regarding burn. Also, this study was agreement with Utsunomiya, et al., (2020) who conducted entitled "Mobilization practices for patients with burn injury in critical care" and found that majority of nurses had unsatisfactory practice about burn. Additionally, this study was supported with Klingberg, et al., (2020) who conducted entitled "Health for Burn Injury Consultations in a Low-Resource Setting: An Acceptability Study among Health Care Providers" and found that majority of nurses had negative attitude regarding burn.

Conversely, this study was disagreement with Carrougher, et al., (2018) who conducted entitled "Burn nurse competencies: developing consensus using E-Delphi Methodology" and found that majority of nurses had satisfactory knowledge regarding burn. Also, this study was disagreement with McCrory, et al., (2018) who conducted entitled "Characteristics of Burn-Injured in 117 US ICUs (2009-2017)" and found that majority of nurses had negative attitude regarding burn in the pre intervention phase

Regarding relation between nurses' knowledge and their personal characteristics, the current study showed that there is a statistically significant relation between nurse's knowledge and their qualifications, experiences in burn department, and training on burn care. While, there is no statistically significant relation between nurse's knowledge and their gender and age.

This study was supported with Lam, Huong, \& Tuan, (2018) who conducted entitled "Nurse Knowledge of emergency management for burn and mass burn injuries" and found that there is a statistically significant relation between nurse's knowledge and their qualifications, and training on burn care. Conversely, this study was disagreement with Mamashli, et al., (2019) who conducted entitled "The effect of self-care compact disk-based instruction program on physical performance and quality of life of patients with burn at-dismissal" and found that there is a statistically significant relation between nurse's knowledge and their gender, qualifications, and marital status.

Regarding relation between nurses' performance and their personal characteristics, the current study showed that there is a statistically significant relation between nurse's practice and their qualifications, experiences in burn department, and training on burn care. While, there is no statistically significant relation between nurse's knowledge and their gender and age.

This study was congruence with Abd Elalem, Shehata., \& Shattla, (2018) who conducted entitled "The effect of self-care nursing intervention model on self-esteem and quality of life among burn patients" and found that there is a statistically significant relation between nurse's practice and their ages, experiences in burn department, and training on burn care. Conversely, this result was disagreement with Ghezeljeh, et al., (2019) who conducted entitled "Investigating the psychosocial empowerment interventions through multimedia education in burn patients" and found that there is highly statistically significant relation between nurse's knowledge and their gender, qualifications, and age.

Regarding relation between nurses' total attitude and their personal characteristics, the current study showed that there is a statistically significant relation between nurse's attitude and their qualifications, experiences in burn department, and training on burn care. While, there is no statistically significant relation between nurse's knowledge and their gender and age.

This study was supported with Rafii, et al., (2017) who conducted entitled "The effect of massage on anticipatory anxiety and procedural pain in patients with burn injury" and found that there is a statistically significant relation between nurse's attitude and their experiences in burn department, and marital status. Also, this study was accordance with $\mathbf{O u}$, et al., (2021) who conducted entitled "Clinical Performance of Hydrogel-based Dressing in Facial Burn Wounds" and found that there is no statistically significant relation between nurse's knowledge and their gender.

Regarding correlation between nurses' total knowledge, practice and attitude scores, the current study shows that there is a positive correlation between nurses' total knowledge, practice and attitude scores.

This study was agreement with Melo, \& Lima, (2017) who conducted entitled "Cost of nursing most frequent procedures performed on severely burned patients" and found that there is a positive correlation between nurses' total knowledge, and their practice. Conversely, this study was disagreement with Ardebili, et al., (2017) who conducted entitled "Effect of multimedia self-care education on quality of life in burn patients" and found that there is negative correlation between nurses' total knowledge, and their attitude.

These may be due to nursing staff seeking for improvement their performance with patients that suffering from burn injury.

\section{Conclusion}

Most of nurses had unsatisfactory knowledge regarding burn. While majority of them had satisfactory practice regarding burn. All of nurses had negative attitude regarding burn. A positive correlation between nurses' total knowledge, practice and attitude scores.

\section{Recommendation}

- Providing continuous education and update for nurses regarding evidence based nursing practices about burn patients.

- Providing supplies and equipment's for burn unit that assist nurses to perform their practice in a high safe and efficient way.

- Continuous observation and accountability by professional supervision.

- Studying nursing burns more broadly in nursing specialty.

\section{References}

(1) Abd Elalem, S. M., Shehata, O. S. M., \& Shattla, S. I. (2018). The effect of self-care nursing intervention model on self-esteem and quality of life among burn patients. Clin Nurs Stud, 6(2), 79-90. 
(2) Ali, H. A., \& Abdel-Hakeim, E. H. (2018). The Effect of Ergonomics Program on Nurses' Knowledge and Practice in Operating Room. Journal of Nursing and Health Science (IOSR-JNHS), 7(1), 6-15.

(3) Ardebili, F. M., Ghezeljeh, T. N., Bozorgnejad, M., Zarei, M., Ghorbani, H., \& Manafi, F. (2017). Effect of multimedia self-care education on quality of life in burn patients. World journal of plastic surgery, 6(3), 292.

(4) Carol ,. A. (2019). Nursing Core Competencies of Staff Nurses Providing Care for Burned Patients. Master Degree in nursing science, Faculty of Nursing, Ain Shams university, PP113-116.

(5) Carrougher, G. J., Hollowed, K. A., Sproul, J. L., Wiggins, B. J., \& Mann-Salinas, E. (2018). Burn nurse competencies: developing consensus using E-Delphi Methodology. Journal of Burn Care \& Research, 39(5), 751-759.

(6) Debra. A., (2018). Effects of a multimodal program including simulation on job strain among nurses working in intensive care units: a randomized clinical trial. Jama, 320(19), 1988-1997.

(7) El-Sayed, et al (2019). Nurse knowledge of burn management. Annals of burns and fire disasters, 31(3), 246.

(8)

(9) Evers. I. (2018). Effect of burn rehabilitation program on improving quality of life (QoL) for hand burns patients: a randomized controlled study. European Journal of Plastic Surgery, 41(4), 451-458.

(10) Ghezeljeh, T. N., Aliha, J. M., Haghani, H., \& Javadi, N. (2019). Effect of education using the virtual social network on the knowledge and attitude of emergency nurses of disaster preparedness: A quasi-experiment study. Nurse education today, 73, 88-93.

(11) Ghezeljeh, T. N., Mamashli, L., Ardebili, F. M., Manafi, F., \& Bozorgnejad, M. (2019). Investigating the psychosocial empowerment interventions through multimedia education in burn patients. World journal of plastic surgery, 8(3), 372.

(12) Hunt. I. (2017). The effect nursing intervention model on quality of life among burn patients. Clin Nurs Stud, 8(5), 111:118.

(13) Joye. I. (2020). The effect of self-care nursing intervention model on self-esteem and quality of life among burn patients. Clin Nurs Stud, 6(2), 79-90.

(14) Kenetra, Eisenbeiss W, Siemers F, Mailander P, et al(2013): Impact of burn care results of an exploratory, retrospective study. 2013;57:30-4.

(15) Klingberg, A., Sawe, H. R., Hammar, U., Wallis, L. A., \& Hasselberg, M. (2020). m-Health for Burn Injury Consultations in a Low-Resource Setting: An Acceptability Study Among Health Care Providers. Telemedicine and eHealth, 26(4), 395-405.
(16) Lam, N. N., Huong, H. T. X., \& Tuan, C. A. (2018). Nurse knowledge of emergency management for burn and mass burn injuries. Annals of burns and fire disasters, 31(3), 246.

(17) Mamashli, L., Ardebili, F. M., Bozorgnejad, M., Ghezeljeh, T. N., \& Manafi, F. (2019). The effect of selfcare compact disk-based instruction program on physical performance and quality of life of patients with burn atdismissal. World journal of plastic surgery, 8(1), 25.

(18) Mayo, F. (2019). Quality of life in burn patients. World journal of plastic surgery, 6(3), 92.

(19) Mehta, K. (2019). The effect of pressure injury training for nurses: A systematic review and meta-analysis. Advances in skin \& wound care, 33(3), 1-11.

(20) Melo, T. D. O., \& Lima, A. F. C. (2017). Cost of nursing most frequent procedures performed on severely burned patients. Revista brasileira de enfermagem, 70(3), 481-488.

(21) Meschial, W. C., \& Oliveira, M. L. F. D. (2017). Initial care for burned patients in academic nursing education.

(22) McCrory, M. C., Woodruff, A. G., Saha, A. K., Halvorson, E. E., Critcher, B. M., \& Holmes IV, J. H. (2021). Characteristics of Burn-Injured in 117 US ICUs (20092017): A Retrospective Virtual Systems Database Study. Critical Care Medicine

(23) Murray, H. (2020). Intensive care unit nurses' performance regarding caring patients with head injury: an educational intervention. International Journal of Studies in Nursing, 3(3), 141.

(24) Ou, K. L., Tzeng, Y. S., Chiao, H. Y., Chiu, H. T., Chen, C. Y., Chu, T. S., .. \& Wu, C. J. (2021). Clinical Performance of Hydrogel-based Dressing in Facial Burn Wounds: A Retrospective Observational Study. Annals of Plastic Surgery, 86(2S), S18-S22.

(25) Rafii, F., Ghezeljeh, T. N., Ardebili, F. M., \& Manafi, F. (2017). The effect of massage on anticipatory anxiety and procedural pain in patients with burn injury. World journal of plastic surgery, 6(1), 40.

(26) Ronald, M. (2016). Investigating the psychosocial empowerment interventions through multimedia education in burn patients. World journal of plastic surgery, 8(3), 372

(27) Tirgari, B., Mirshekari, L., \& Forouzi, M. A. (2018). Pressure injury prevention: knowledge and attitudes of Iranian intensive care nurses. Advances in skin \& wound care, 31(4), 1-8.

(28) Utsunomiya, K. F., de Figueiredo, T. B., de Oliveira, A. M. R. R., Pires-Neto, R. C., \& Tanaka, C. (2020). Mobilization practices for patients with burn injury in critical care. Burns, 46(2), 314-321.

(29) Wysocki, A., (2019). The effect of self-care compact diskbased instruction program on physical performance and quality of life of patients with burn at-dismissal. World journal of plastic surgery, 8(1), 25 